\title{
Impact of using different ozone cross sections on ozone profile retrievals from Global Ozone Monitoring Experiment (GOME) ultraviolet measurements
}

\author{
X. Liu ${ }^{1,2}$, K. Chance ${ }^{1}$, C. E. Sioris ${ }^{1,3}$, and T. P. Kurosu ${ }^{1}$ \\ ${ }^{1}$ Atomic and Molecular Physics Division, Harvard-Smithsonian Center for Astrophysics, Cambridge, MA, USA \\ ${ }^{2}$ Goddard Earth Sciences and Technology Center, University of Maryland Baltimore County, Baltimore, MD, USA \\ ${ }^{3}$ Atmospheric Science and Technology Directorate, Environment Canada, Toronto, ON, Canada
}

Received: 25 September 2006 - Published in Atmos. Chem. Phys. Discuss.: 19 January 2007

Revised: 19 June 2007 - Accepted: 28 June 2007 - Published: 6 July 2007

\begin{abstract}
We investigate the effect of using three different cross section data sets on ozone profile retrievals from Global Ozone Monitoring Experiment (GOME) ultraviolet measurements $(289-307 \mathrm{~nm}, 326-337 \mathrm{~nm})$. These include Bass-Paur, Brion, and GOME flight model cross sections (references below). Using different cross sections can significantly affect the retrievals, by up to 12 Dobson Units (DU, $1 \mathrm{DU}=2.69 \times 10^{16}$ molecules $\mathrm{cm}^{-2}$ ) in total column ozone, up to $10 \mathrm{DU}$ in tropospheric column ozone, and up to $100 \%$ in retrieved ozone values for individual atmospheric layers. Compared to using the Bass-Paur and GOME flight model cross sections, using the Brion cross sections not only reduces fitting residuals by $15-60 \%$ in the Huggins bands, but also improves retrievals, especially in the troposphere, as seen from validation against ozonesonde measurements. Therefore, we recommend using the Brion cross section for ozone profile retrievals from ultraviolet measurements. The total column ozone retrieved using the GOME flight model cross sections is systematically lower, by 7-10 DU, than that retrieved using the Brion and Bass-Paur cross sections and is also systematically lower than Total Ozone Mapping Spectrometer (TOMS) observations. This study demonstrates the need for improved ozone cross section measurements in the ultraviolet to improve profile retrievals of this key atmospheric constituent.
\end{abstract}

\section{Introduction}

Chance et al. (1997) demonstrated that ozone profile including tropospheric ozone can be derived from nadir-viewing ul-

Correspondence to: X. Liu

(xliu@umbc.edu) traviolet/visible radiance spectra utilizing the Hartley, Huggins and Chappuis ozone absorption bands. The photon penetration into the troposphere in the Huggins and Chappuis bands and the temperature-dependent vibrational structures in the Huggins bands provide information about tropospheric ozone. This idea has been applied to Global Ozone Monitoring Experiment (GOME) ultraviolet measurements by several groups (Munro et al., 1998; Hoogen et al., 1999; Hasekamp and Landgraf, 2001; van der A et al., 2002; Liu et al., 2005). However, it is important to fit the Huggins bands to a high precision (e.g., <0.1\%) (Munro et al., 1998) for retrieving tropospheric ozone. In addition to extensive wavelength and radiometric calibrations and forward radiative transfer modeling (Liu et al., 2005), the quality of spectroscopic ozone cross sections (CS) including the wavelength and absolute accuracy is critical to reducing fitting residuals and improving the quality of retrieved profiles, especially in the troposphere.

Orphal $(2002,2003)$ critically reviewed available ultraviolet ozone CS that cover a wide range of atmospheric temperatures. He found that three sets of ozone CS have an overall agreement of $1-2 \%$ after accounting for wavelength shifts, baseline effects, and spectral resolution. These include: (1) Bass-Paur CS (Bass and Paur, 1985; Paur and Bass, 1985) (abbreviated as BP), (2) Brion CS (Daumont et al., 1992; Brion et al., 1993; Malicet et al., 1995) (abbreviated as BDM), and (3) GOME flight model CS (Burrows et al., 1999) (abbreviated as GMFM). The BP and BDM CS are especially close, within $1 \%$ (Orphal, 2002). Table 1 summarizes the spectroscopic measurement characteristics of these CS (Orphal, 2002). The BP CS are widely used in the scientific community for total column ozone and ozone profile retrievals and are currently included in the HITRAN database

Published by Copernicus Publications on behalf of the European Geosciences Union. 
Table 1. Measurement characteristics of three laboratory ozone cross sections.

\begin{tabular}{llll}
\hline & Bass-Paur & BDM & GOME FM \\
\hline Instrument & scanning monochromator & $\begin{array}{l}\text { Jobin Yvon THR1500 \& } \\
640 \\
\end{array}$ & $\begin{array}{l}\text { monochromator with } \\
\text { spectrometer } \\
\text { diode-array detectors }\end{array}$ \\
Wavelength (nm) & $245-343$ & $195-830^{1}$ & \\
Spectral Res. (nm) & 0.025 & $0.01-0.02$ & $231-794$ \\
Temperature (K) & $203,218,228,243$, & $218,228,243,273$, & $0.2-0.4$ \\
& $273,298^{2}$ & 295 & $202,221,241,273$, \\
Data Sampling (nm) & 0.05 & $0.01 \quad$ GOME wavelength \\
& & & Daumont et al. (1992); \\
References & Bass and Paur (1985); & Burrows et al. (1999) \\
& Paur and Bass (1985) & Malicet et al. (1995) & \\
\hline
\end{tabular}

$1300-345 \mathrm{~nm}$ at $273 \mathrm{~K}, 195-345 \mathrm{~nm}$ at $228 \mathrm{~K}, 243 \mathrm{~K}$, and $273 \mathrm{~K}, 195-345 \mathrm{~nm}$ and $515-650 \mathrm{~nm}$ at $218 \mathrm{~K}$.

2 Quadratic coefficients at each wavelength.

(Rothman et al., 2005) as a standard, after applying a wavelength shift of $+0.015 \mathrm{~nm}$ (Orphal and Chance, 2003). However, they are noisier than the others (Orphal, 2002). The BDM CS are found to have better wavelength calibration than the BP data (Orphal, 2002). However, since they do not cover temperatures below $218 \mathrm{~K}$, they are not included in the HITRAN database. To our knowledge, the BDM CS have not been used in remote sensing of ozone in the literature except in our algorithm (Liu et al., 2005). Although the the GMFM CS have a relatively coarse spectral resolution of $0.2-0.4 \mathrm{~nm}$, they might be better used for GOME ozone profile retrievals since they have been measured by the same GOME instrument. GMFM CS are currently being used in the GOME operational total ozone algorithm (van Roozendael et al., 2006) and were used in the GOME ozone profile retrieval by Hoogen et al. (1999).

To evaluate the impacts of using these sets of ozone CS on ozone profile retrievals and determine which CS should be used in retrieving ozone profiles from ultraviolet measurements, we compare retrievals with these CS using our GOME ozone profile retrieval algorithm. We also compare the retrievals near ozonesonde stations at Hohenpeißenberg $\left(47.9^{\circ} \mathrm{N}, 11.0^{\circ} \mathrm{E}\right)$ and Hilo $\left(155.1^{\circ} \mathrm{W}, 19.6^{\circ} \mathrm{N}\right)$ with coincident Total Ozone Mapping Spectrometer (TOMS) and ozonesonde measurements.

\section{Ozone profile retrieval algorithm and comparison methodology}

The ozone profile retrieval algorithm was described in detail in Liu et al. (2005). Briefly, ozone profiles are retrieved at 11 layers (each layer is about $5 \mathrm{~km}$ thick except the top layer which is $\sim 10 \mathrm{~km}$ thick) from reflectance spectra for 289 $307 \mathrm{~nm}$ (in GOME channel 1) and 326-339 nm (in GOME channel 2) using the optimal estimation technique, after extensive wavelength and radiometric calibrations and forward modeling of atmospheric ozone, temperature, clouds, aerosols, and surface albedo. We use the ozone profile climatology by McPeters et al. (2007) as a priori to constrain the retrievals. A wavelength-dependent shift (3rd-order polynomial) in ozone CS relative to the calibrated radiance spectrum is fitted in the retrieval for each fitting window to calibrate the wavelengths of ozone CS. Wavelength-dependent slit widths are pre-determined by cross-correlating the solar irradiance spectra with a high-resolution solar reference spectrum (Liu et al., 2005). The tropopause from the National Centers for Environmental Prediction/National Center for Atmospheric Research (NCEP/NCAR) reanalysis is used to separate the troposphere and stratosphere; there are 2-3 tropospheric layers. Daily temperature profiles from the European Center for Medium range Weather Forecasting model (ECMWF) are used to reduce the effect of temperature on retrievals. Three major changes have been made to this algorithm for the current study. First, ozone profiles are retrieved for 24 layers (each layer is $\sim 2.5 \mathrm{~km}$ thick) with 4-6 tropospheric layers. Second, the fitting window of $326-339 \mathrm{~nm}$ is changed to $326-337 \mathrm{~nm}$ because the BP CS only covers up to $343 \mathrm{~nm}$ and a few nanometers are needed on each end of the fitting window to model the Ring effect. Third, we switched to use daily NCEP/NCAR temperature profiles for consistency during the GOME record since ECMWF temperature profiles are not publicly available after August 2002.

We use exactly the same retrieval algorithm for different CS except with some necessary modifications to the original CS described as follows. The BP data are provided as temperature-dependent quadratic coefficients so that they can be conveniently applied to any atmospheric temperature. Their wavelengths, originally in air, have been previously converted to vacuum wavelengths (Orphal and Chance, 
2003). The other two ozone CS are given at individual temperatures and at air wavelengths. We do not use the BDM CS at $273 \mathrm{~K}$ in the fitting for two reasons. First, the $273 \mathrm{~K} \mathrm{CS}$ do not extend below $300 \mathrm{~nm}$, so we exclude them to avoid inconsistency over the whole fitting window. Second, we find that including the $273 \mathrm{~K} \mathrm{CS}$ in the parameterization of the temperature dependence above $300 \mathrm{~nm}$ leads to much larger CS residuals (Fig. 1a) at all other temperatures than residuals obtained excluding the $273 \mathrm{~K} \mathrm{CS}$ (Fig. 1b). It seems that a systematic bias exists at $273 \mathrm{~K}$ relative to other temperatures in the BDM measurements. Because the BDM and BP CS are measured at high spectral resolution, we convolve them to the GOME spectral resolution with the pre-determined variable slit widths. The GMFM CS do not need to be convolved because they were measured at GOME resolution.

Figure 2 compares different ozone CS at three temperatures that are actually used in individual retrievals. These CS are wavelength-calibrated and transformed to the same spectral resolution during the retrieval. For 289-307 nm, the BP CS compare with the BDM CS to within $\sim 1 \%$, with small mean biases, while the GMFM CS are on average higher by $1-2 \%$ than the BDM CS. For $326-337 \mathrm{~nm}$, the mean BP (GMFM) CS are higher by 1-2\% (2-4\%) than the BDM CS. Applying additional shifts among different CS only slightly reduces these mean biases. The biases at individual wavelengths show large spectral variation and can be as high as $8 \%$. The strong and frequent oscillating structures present in Fig. $2 b$ support the observation that the BP CS are noisier. This may result from worse wavelength calibration because the BP CS were measured by a step-scanning monochromator, one wavelength at a time. Differences also occur in the temperature dependences, especially between the GMFM and BDM CS because the biases vary significantly with temperature. It should be noted that these biases are significantly larger than those found by Orphal (2002). This is because he compared these CS at individual temperatures (temperature usually within $\pm 5 \mathrm{~K}$ between different sets) and accounted for baseline effects.

To evaluate the effects of using different CS on ozone profile retrievals, we compare the retrievals during overpasses of Hohenpeißenberg in 1997 and Hilo in 1996-1999 against TOMS total column ozone (TO), ozonesonde ozone profile and tropospheric column ozone (TCO). TOMS TO data are obtained from http://toms.gsfc.nasa.gov. Ozonesonde data at Hohenpeißenberg are obtained from the World Ozone and Ultraviolet Data Center (WOUDC, http://www. woudc.org) and ozonesonde data at Hilo, normalized with simultaneously observed Dobson TO, are obtained from http://www.cmdl.noaa.gov. The collocation criteria and methods to compare retrievals with other correlative measurements have been described in detail in Liu et al. (2005, 2006).
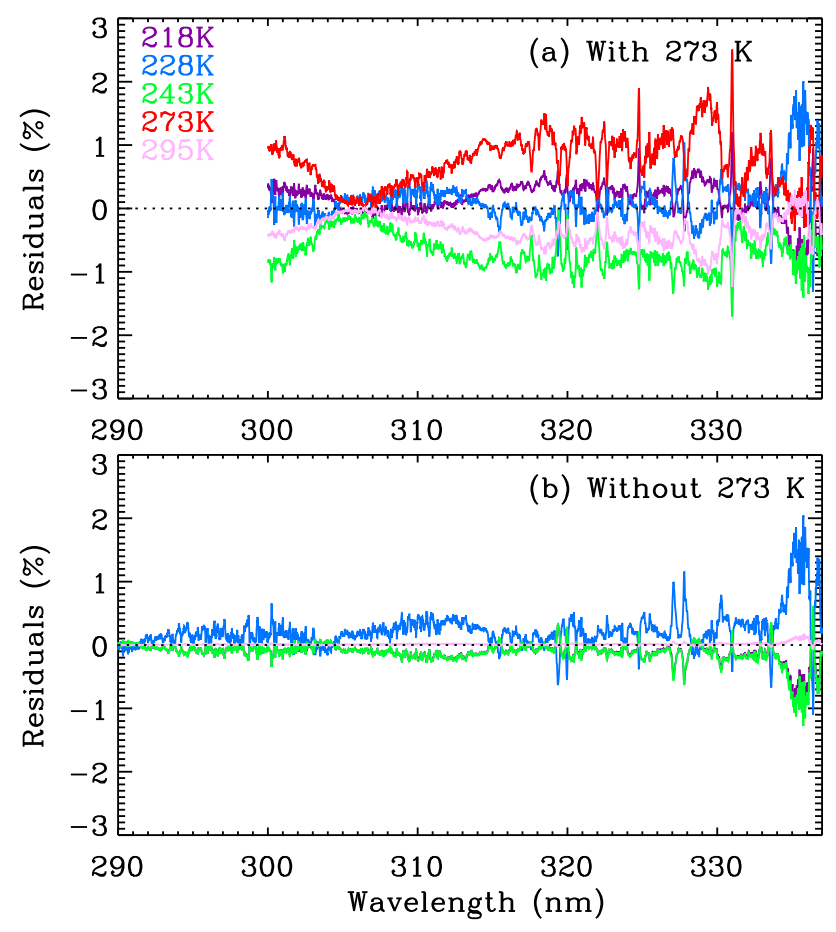

Fig. 1. Residuals in ozone cross sections at different temperatures after using non-linear least squares fitting to derive quadratic temperature-dependent coefficients from the original Brion cross sections. (a) With 273 K. (b) Without 273 K.

\section{Comparison of retrievals}

Figure 3 and Table 2 compares the average fitting residuals in the two fitting windows for an orbit of retrievals (orbit 70607024). In the $289-307 \mathrm{~nm}$ region, where ozone absorption features are broad, the fitting residuals are similar between different CS, except that using the BDM CS reduces the fitting residuals by $4-7 \%$ (relative to the fitting residuals). For $326-337 \mathrm{~nm}$, where there are relatively narrow vibrational structures, the average fitting residuals with the BDM CS are smaller by $20-60 \%$ and $16-50 \%$ (relative to the fitting residuals) than those with the BP and GMFM CS, respectively. In addition, the residuals with the BDM CS do not vary much with latitude (or solar zenith angle), while the residuals with the other two CS increase with latitude. Since ozone absorption varies with latitude resulting from the increase of solar zenith angle at higher latitude and the latitudinal distribution of ozone, generally decreasing toward the equator, this indicates a problem with fitting the ozone absorption in the observed spectra for the GMFM and BP CS. The differences in residuals are similar for the retrievals of orbit 61201030 and the overpasses of Hohenpeißenberg and Hilo (Table 2). The residual differences support the BDM CS having the best wavelength calibration and the BP CS being the noisiest (Orphal, 2002). Table 2 also compares the number of successful retrievals. Using the BDM CS generally 


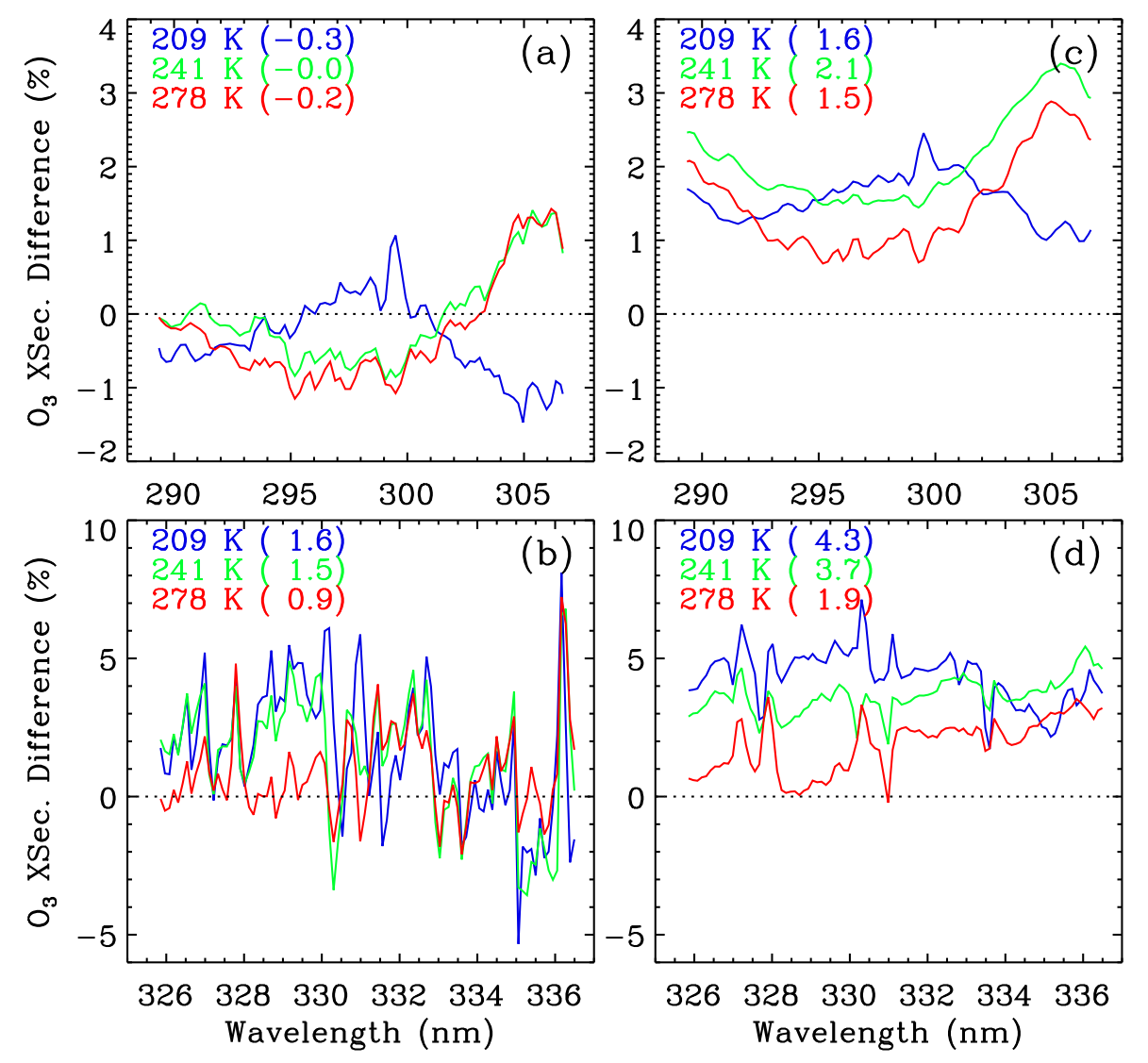

Fig. 2. (a-b) Differences between Bass-Paur and Brion cross sections for the 289-307 and 326-337 nm ranges, respectively, at three temperatures. (c-d) Like (a-b) but for differences between GOME flight model and Brion cross sections. The numbers in parentheses indicate the mean bias.

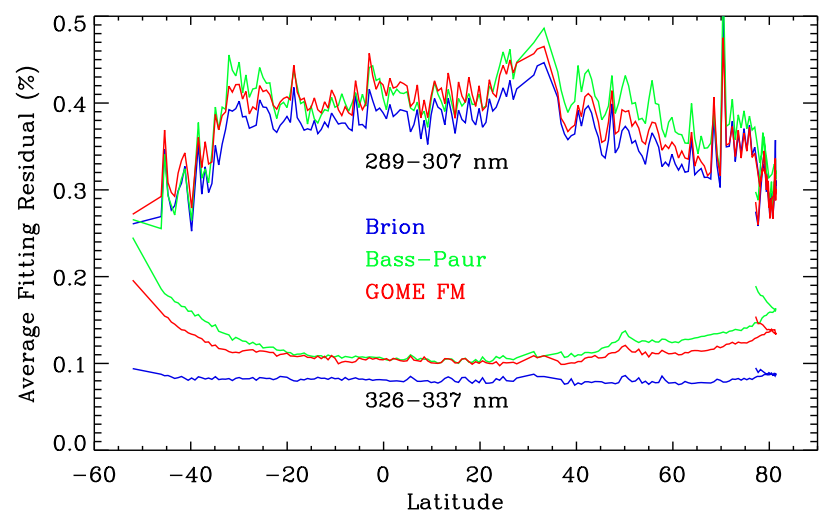

Fig. 3. Average fitting residuals using different ozone cross sections as a function of latitude for an orbit of retrievals (70607024) in two fitting windows (289-307 and 326-337 nm).

leads to more successful retrievals. Unsuccessful retrievals are due mainly to negative ozone values derived at some layers.
Figures 4-6 compare the retrieved TO, TCO, and ozone profiles for the same orbit as in Fig. 3. The TO retrieved with the BP and BDM CS are generally consistent, with the former smaller by 1-2 Dobson Units (DU, $1 \mathrm{DU}=2.69 \times 10^{16}$ molecules $\mathrm{cm}^{-2}$ ) or $\sim 0.5-1.0 \%$. The retrieved TO with the GMFM CS is smaller relative to the TO with the BDM CS, ranging from $\sim 6 \mathrm{DU}(\sim 2.5 \%)$ in $30^{\circ} \mathrm{S}-$ $40^{\circ} \mathrm{N}$ to $12 \mathrm{DU}(\sim 4.0 \%$ ) at higher latitudes (Fig. 4). Table 2 indicates that similar TO biases exist for other retrievals with the GMFM CS. The reason for the smaller TO retrieved with the GMFM CS is that these CS are systematically larger by $>1.5 \%$ in both fitting windows (Fig. 2). The retrieved TCO also shows biases of up to $10 \mathrm{DU}(30 \%)$ at some locations, although the biases are not a smooth function of latitude. The BP retrievals show negative biases of $<3$ DU $(\sim 10 \%)$ at most locations relative to the BDM retrievals but show negative biases of $5-10 \mathrm{DU}(\sim 15-30 \%)$ at $20^{\circ}-40^{\circ} \mathrm{N}$. The GMFM retrievals show negative biases of $>5$ DU $(\sim 15 \%)$ at most locations relative to the BDM retrievals but show small negative biases or even positive biases at higher latitudes and around $40^{\circ} \mathrm{N}$ and $45^{\circ} \mathrm{N}$. On average, the retrieved TCO values with the BP and GMFM CS are lower by $1-5$ DU 
Table 2. Comparisons of number of successful retrievals $\left(\mathrm{N}_{\text {ret }}\right)$, fitting residuals in two windows $\left(\mathrm{R}_{1}\right.$ and $\left.\mathrm{R}_{2}\right)$, retrieved total column ozone (TO), and tropospheric column ozone (TCO) for two orbits of retrievals and retrievals coincident with Hohenpeißenberg and Hilo.

\begin{tabular}{lllll}
\hline Orbit/Station & & BDM & Bass-Paur & GOME FM \\
\hline \multirow{4}{*}{ Orbit 70607024 } & $\mathrm{N}_{\text {ret }}$ & 201 & 196 & 200 \\
& $\mathrm{R}_{1 / \mathrm{R}_{2}(\%)}$ & $0.36 / 0.08$ & $0.38 / 0.13$ & $0.38 / 0.12$ \\
& $\mathrm{TO} / \mathrm{TCO}(\mathrm{DU})$ & $304.6 / 30.4$ & $303.5 / 27.8$ & $296.0 / 27.5$ \\
& $\mathrm{~N}_{\text {ret }}$ & 192 & 167 & 183 \\
Orbit 61201030 & $\mathrm{R}_{1 / \mathrm{R}_{2}(\%)}$ & $0.34 / 0.08$ & $0.37 / 0.12$ & $0.37 / 0.11$ \\
& $\mathrm{TO} / \mathrm{TCO}(\mathrm{DU})$ & $283.5 / 24.8$ & $282.9 / 22.9$ & $276.4 / 22.0$ \\
& $\mathrm{~N}_{\text {ret }}$ & 235 & 233 & 233 \\
Hohenpeißenberg (1997) & $\mathrm{R}_{1 / \mathrm{R}_{2}(\%)}$ & $0.34 / 0.08$ & $0.38 / 0.14$ & $0.38 / 0.13$ \\
& $\mathrm{TO}_{\mathrm{TCO}}(\mathrm{DU})$ & $319.9 / 33.0$ & $318.2 / 28.3$ & $308.7 / 32.1$ \\
& $\mathrm{~N}_{\text {ret }}$ & 305 & 302 & 297 \\
Hilo (1996-1999) & $\mathrm{R}_{1 / \mathrm{R}}(\%)$ & $0.41 / 0.08$ & $0.43 / 0.11$ & $0.43 / 0.10$ \\
& $\mathrm{TO} / \mathrm{TCO}(\mathrm{DU})$ & $271.3 / 33.7$ & $270.5 / 30.5$ & $264.5 / 28.4$ \\
\hline
\end{tabular}

Table 3. Comparison statistics: number of comparisons n, mean bias (DU), standard deviation (DU) and correlation coefficient between retrieved total column ozone (TO) and tropospheric column ozone (TCO) with TOMS and ozonesonde observations at Hohenpeißenberg and Hilo for different cross sections.

\begin{tabular}{lllll}
\hline \multicolumn{5}{c}{ Hohenpeißenberg (1997) } \\
\hline \multirow{2}{*}{ TOMS TO } & $\mathrm{n}$ & BDM & Bass-Paur & GOME FM \\
Sonde TCO & 207 & $2.6 \pm 5.3,0.99$ & $1.2 \pm 5.6,0.99$ & $-7.4 \pm 5.4,0.99$ \\
& 77 & $0.3 \pm 3.4,0.76$ & $-4.1 \pm 3.8,0.78$ & $-1.0 \pm 3.8,0.72$ \\
\hline \multicolumn{5}{c}{ Hilo (1996-1999) } \\
TOMS TO & 222 & $-0.7 \pm 2.9,0.98$ & $-1.9 \pm 2.8,0.98$ & $-8.0 \pm 2.8,0.99$ \\
Sonde TCO & 52 & $0.3 \pm 5.6,0.85$ & $-2.7 \pm 6.2,0.81$ & $-4.8 \pm 6.4,0.80$ \\
\hline
\end{tabular}

( $\sim 3-15 \%)$, depending on the locations (Table 2). Figure 6 shows that the mean retrieved ozone profiles with the BP and GMFM CS are generally smaller by $15 \%$ at individual layers especially below $20 \mathrm{~km}$. The individual retrieved profiles occasionally show both positive and negative biases of up to 50-100\% between the BP/GMFM and BDM CS in the tropical and Antarctic upper troposphere and lower stratosphere, where the ozone amount is small.

Figures 7-9 compare retrievals with different CS against the TOMS TO, ozonesonde TCO and profiles over Hohenpeißenberg and Hilo. Table 3 summarizes the TO and TCO comparison. The retrieved TO with the BDM and BP CS compares well with TOMS TO, to within $3 \mathrm{DU}(\sim 1 \%)$ on average. However, the BDM has slightly smaller standard deviations. The TO retrieved with the GMFM CS shows systematic negative biases of $7-8 \mathrm{DU}(\sim 2-3 \%)$ relative to TOMS TO, but the standard deviations and correlations are slightly better than those with the BP CS. As for TCO, the retrievals with the BDM CS consistently show better agreement (i.e., smaller biases and standard deviations, and higher correlation) with ozonesonde TCO than the others at these
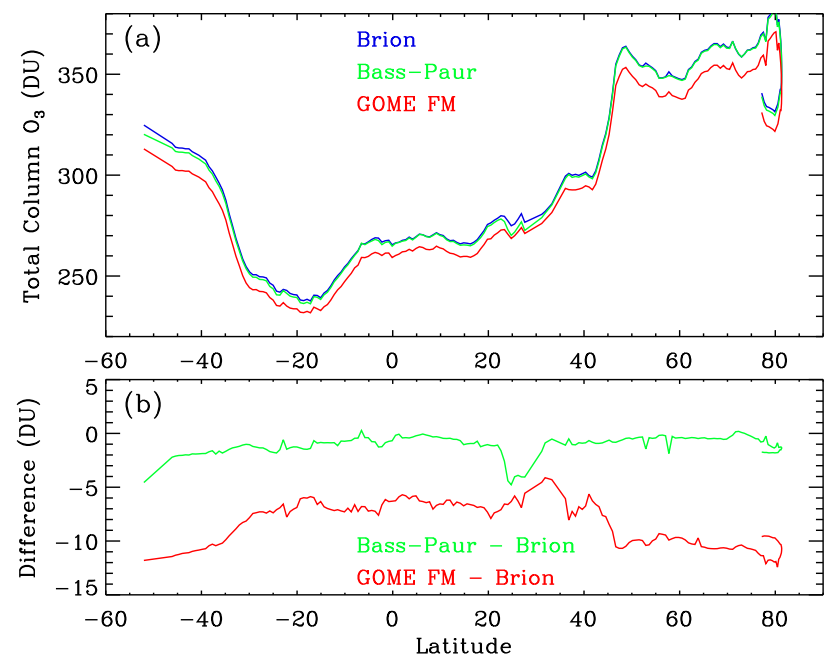

Fig. 4. Comparison of (a) the retrieved total column ozone using different ozone cross sections for the same orbit as in Fig. 3 and (b) their differences. 

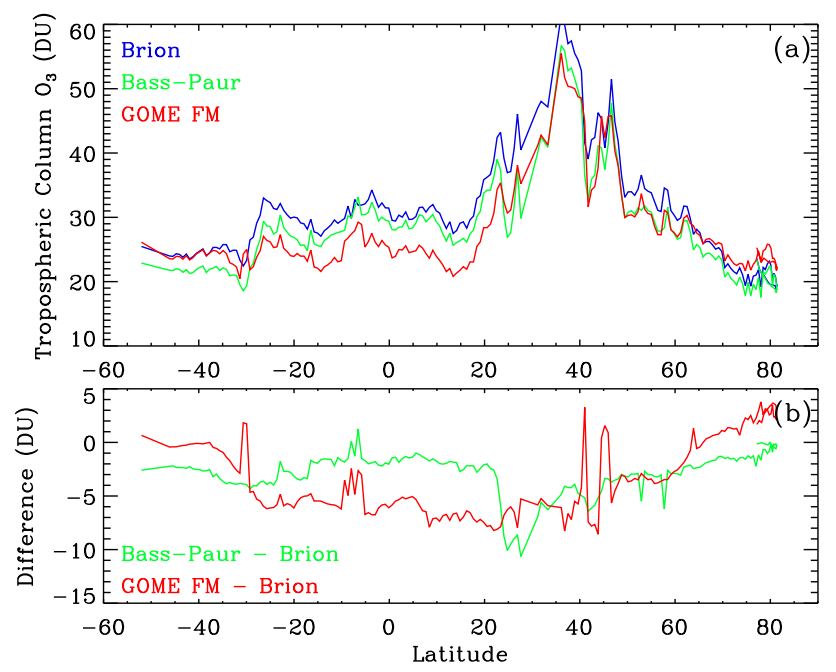

Fig. 5. Same as Fig. 4 but for the retrieved tropospheric column ozone.
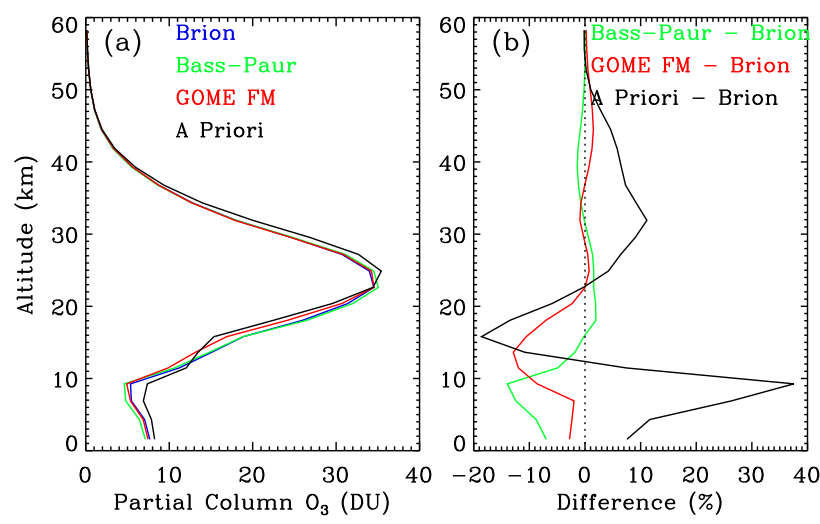

Fig. 6. Comparison of (a) mean a priori and retrieved ozone profiles using different ozone cross sections for the same orbit as in Fig. 3 and (b) their differences.

two locations. The mean biases with the BDM CS are within $0.5 \mathrm{DU}(1-2 \%)$, while the BP retrievals have a negative mean bias of $4 \mathrm{DU}(\sim 10 \%)$ at Hohenpeißenberg and the GMFM retrievals have a negative mean bias of $5 \mathrm{DU}(\sim 15 \%)$ at Hilo. The GMFM TCO shows slightly worse standard deviations and correlation coefficients than the others. Figure 9 illustrates that there are large relative biases below $20 \mathrm{~km}$ (up to $30 \%$ at Hohenpeißenberg and up to $60 \%$ at Hilo) between using different CS, consistent with the results in Fig. 6. The retrievals with the BDM CS show positive biases of up to $30 \%$ between 10 and $20 \mathrm{~km}$. These biases, investigated in detail in Liu et al. (2006), are due to a combination of retrieval errors (e.g., wavelength-dependent bias in the GOME channel 1a reflectance) and ozonesonde measurements (e.g., uncorrected hysteresis). The fact that GMFM retrievals compare best with ozonesonde measurements at Hohenpeißen-
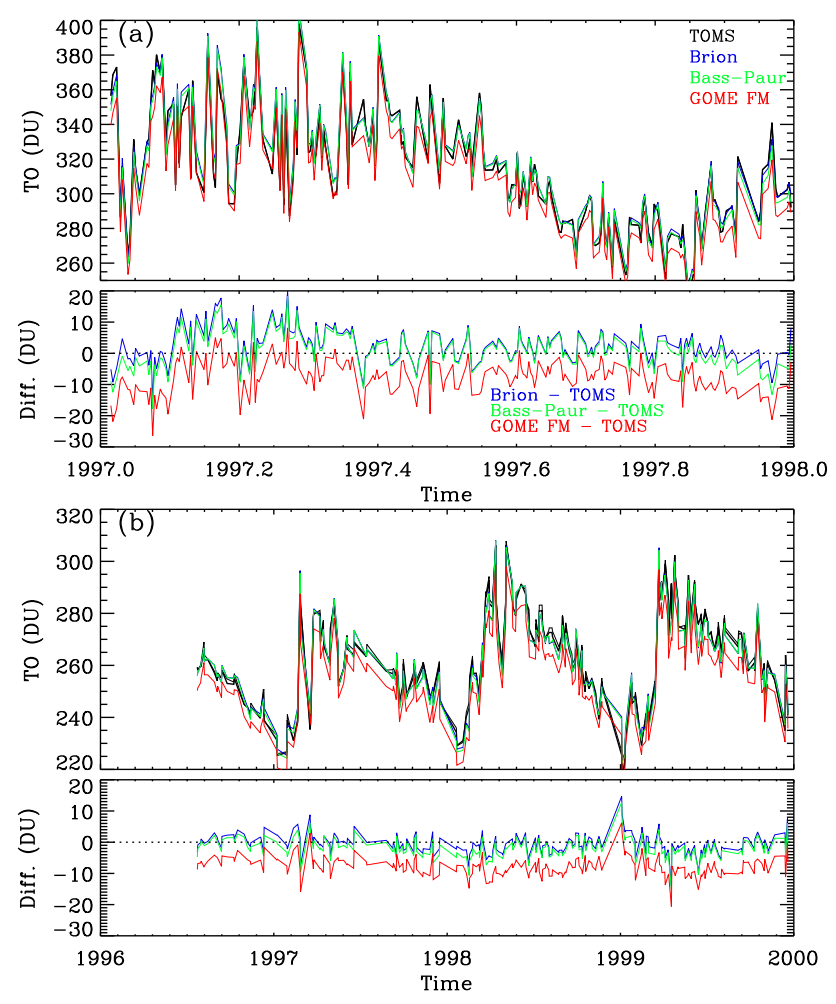

Fig. 7. Comparison of total column ozone (TO) retrieved with different cross sections, and TOMS TO, and their differences. (a) Hohenpeißenberg during 1997. (b) Hilo during 1996-1999.

berg below $20 \mathrm{~km}$ is likely due to canceling errors: at Hilo, the GMFM retrievals have negative biases of $10-30 \%$ below $20 \mathrm{~km}$. The BP retrievals have positive biases above $\sim 10 \mathrm{~km}$ and negative biases below $\sim 10 \mathrm{~km}$.

\section{Summary and discussion}

To investigate the effects of ozone cross sections (CS) on ozone profile retrievals, we compared retrievals using our GOME ozone profile algorithm with three CS data sets: Bass-Paur (BP), Brion (BDM), and GOME flight model (GMFM). After transforming these CS to the same GOME spectral resolution and calibrating wavelengths through the retrieval processes, we find that systematic differences exist among different CS. For example, the BP CS have a positive mean bias of $1-2 \%$ in $326-337 \mathrm{~nm}$ relative to the BDM CS; the GMFM CS have positive mean biases of $2 \%$ in 289 $307 \mathrm{~nm}$ and $2-4 \%$ in $326-337 \mathrm{~nm}$. The biases depend on temperature, especially between the BDM/BP and GMFM CS.

We find that using the BDM CS significantly reduces fitting residuals, by $20-60 \%$ and $15-50 \%$ in the Huggins bands, compared to using the BP and GMFM CS, respectively. Due to the systematic differences and different uncertainties in 

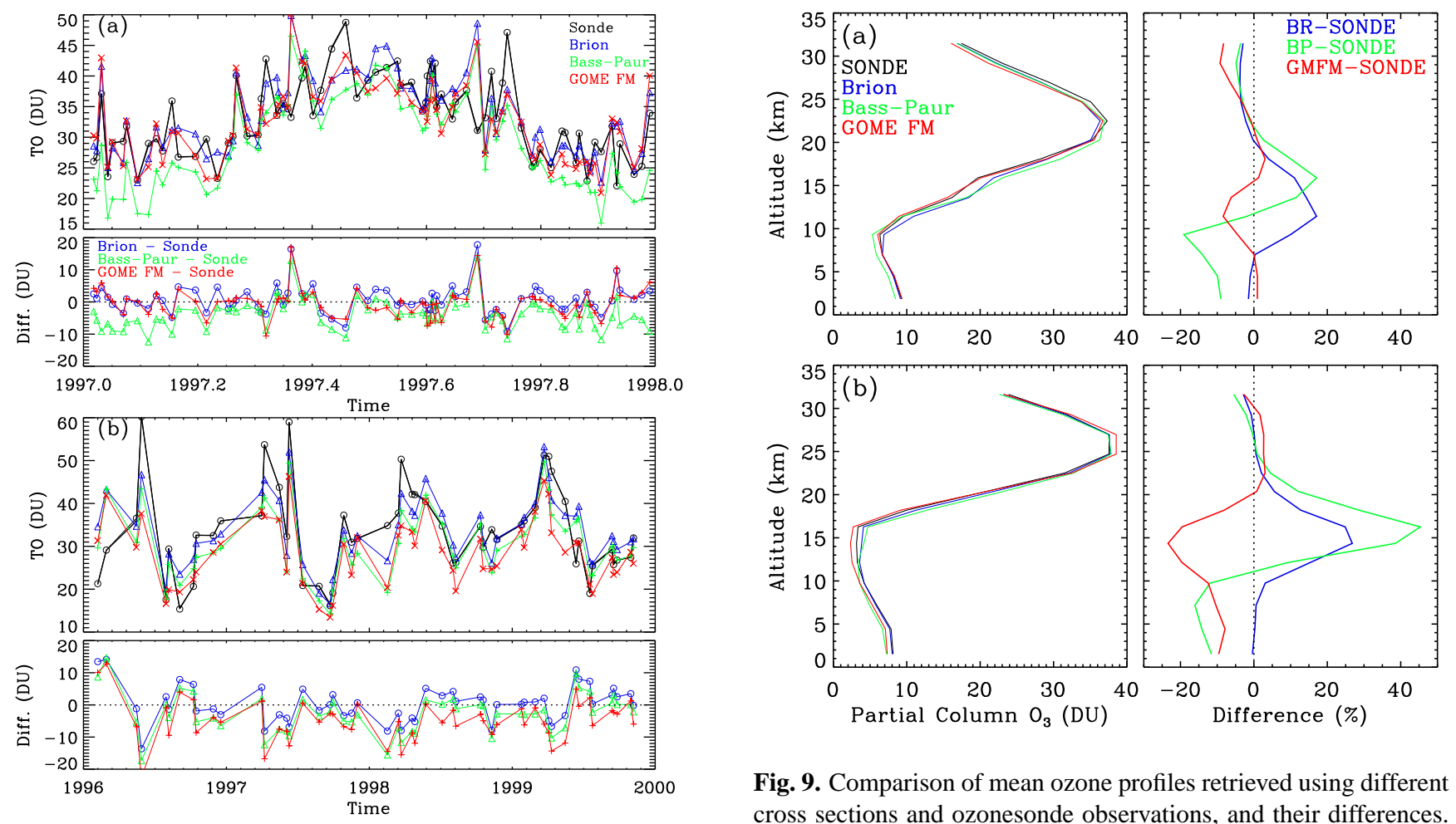

Fig. 8. Same as Fig. 7 but for retrieved and ozonesonde tropospheric column ozone.

these CS, the choice of CS significantly impacts retrievals, by up to $12 \mathrm{DU}$ in total column ozone (TO), $10 \mathrm{DU}$ in tropospheric column ozone (TCO), and $\sim 100 \%$ in ozone values at individual layers. The TO values retrieved with the BDM and BP CS are similar, with the former larger by 1$2 \mathrm{DU}$ on average. Both agree with the TOMS TO values to within 3 DU. The GMFM TO values are lower, by 7-10 DU on average, than the BDM and BP TO values and are lower by 7-8 DU than the TOMS TO values. Through validation against ozonesonde TCO at Hohenpeißenberg and Hilo, we find that retrievals with the BDM CS generally compare best with ozonesonde TCO, leading to smaller biases and standard deviations, and higher correlation coefficients.

Based on this study, we recommend the use of the BDM CS for ozone profile retrievals from ultraviolet measurements and recommend the inclusion of this data set in the HITRAN database. However, it should be noted that there are certain limitations in using BDM CS. First, they do not cover the temperature range below $218 \mathrm{~K}$, while the atmospheric temperature in the upper troposphere and lower stratosphere is often below $218 \mathrm{~K}$, as low as $\sim 195 \mathrm{~K}$. Second, the $273 \mathrm{~K}$ CS seem to contain systematic biases relative to CS at other temperatures and do not extend below $300 \mathrm{~nm}$. Third, Orphal (2002) reported that the BDM data contain some nonlinear wavelength calibration errors. To effectively use this data set, we have to rely on the quadratic coefficients de-

Fig. 9. Comparison of mean ozone profiles retrieved using different cross sections and ozonesonde observations, and their differences. (a) Hohenpeißenberg during 1997. (b) Hilo during 1996-1999.

rived from four temperatures (i.e., 218, 228, 243, and $295 \mathrm{~K}$ ). This can introduce errors in the CS actually used in retrievals especially below $218 \mathrm{~K}$ as well as to the temperature dependence of ozone absorption, which is important for tropospheric ozone retrievals. Therefore, we require superior ultraviolet ozone CS measured at high spectral resolution, with better wavelength calibrations and accuracy, and covering a wide range of atmospheric temperatures. In view of the emerging methods of deriving tropospheric and even boundary layer ozone by combing ultraviolet, visible, and infrared measurements for air quality monitoring, it is essential that ozone absorption cross sections in different spectral regions are consistent.

Acknowledgements. This study is supported by NASA and the Smithsonian Institution. We thank the WOUDC and CMDL and their data originators for providing ozonesonde measurements and the TOMS data processing team for providing the TOMS data.

Edited by: U. Platt

\section{References}

Bass, A. M. and Paur, R. J.: The ultraviolet cross-sections of ozone, I, The measurements, in: Atmospheric Ozone, edited by: Zerefos, C. S., Ghazi, A., and Reidel, D., Norwell, Mass., 606-610, 1985.

Brion, J., Chakir, A., Charbonnier, J., Daumont, D., Parisse, C., and Malicet, J.: Absorption spectra measurements for the ozone 
molecule in the 350-830 nm region, J. Atmos. Chem., 30, 291299, 1998.

Brion, J., Chakir, A., Daumont, D., and Malicet, J.: High-resolution laboratory absorption cross section of $\mathrm{O}_{3}$. Temperature effect, Chem. Phys. Lett., 213(5-6), 610-512, 1993.

Burrows, J. P., Dehn, A., Deters, B., Himmelmann, S., Richter, A., Voigt, S., and Orphal, J.: Atmospheric remote-sensing reference data from GOME: Part 2. Temperature-dependent absorption cross-sections of $\mathrm{O}_{3}$ in the 231-794 nm range, J. Quant. Spectrosc. Radiat. Transfer, 61(4), 509-517, 1999.

Chance, K. V., Burrows, J. P., Perner, D., and Schneider, W.: Satellite measurements of atmospheric ozone profiles, including tropospheric ozone, from ultraviolet/visible measurements in the nadir geometry: a potential method to retrieve tropospheric ozone, J. Quant. Spectrosc. Radiat. Transfer, 57(4), 467-476, 1997.

Daumont, M., Brion, J., Charbonnier, J., and Malicet, J.: Ozone UV spectroscopy I: Absorption cross-sections at room temperature, J. Atmos. Chem., 15, 145-155, 1992.

Hasekamp, O. P. and Landgraf, J.: Ozone profile retrieval from backscattered ultraviolet radiances: The inverse problem solved by regularization, J. Geophys. Res., 106(D8), 8077-8088, 2001.

Hoogen, R., Rozanov, V. V., and Burrows, J. P.: Ozone profiles from GOME satellite data: Algorithm description and first validation, J. Geophys. Res., 104(D7), 8263-8280, 1999.

Liu, X., Chance, K., Sioris, C. E., Spurr, R. J. D., Kurosu, T. P., Martin, R. V., and Newchurch, M. J.: Ozone profile and tropospheric ozone retrievals from Global Ozone Monitoring Experiment: Algorithm description and validation, J. Geophys. Res., 110(D20), D20307, doi:10.1029/2005JD006240, 2005.

Liu, X., Chance, K., Sioris, C. E., Kurosu, T. P., and Newchurch, M. J.: Intercomparison of GOME, ozonesonde, and SAGE-II measurements of ozone: Demonstration of the need to homogenize available ozonesonde datasets, J. Geophys. Res., 101(D14), D114305, doi:10.1029/2005JD006718, 2006.
Malicet, C., Daumont, D., Charbonnier, J., Parisse, C., Chakir, A., and Brion, J.: Ozone UV spectroscopy, II. Absorption crosssections and temperature dependence, J. Atmos. Chem., 21, 263273, 1995.

McPeters, R. D., Labow, G. J., and Logan, J. A.: Ozone climatological profiles for satellite retrieval algorithms, J. Geophys. Res., 112(D5), D05308, doi:10.1029/2005JD006823, 2007.

Munro, R., Siddans, R., Reburn, W. J., and Kerridge, B.: Direct measurement of tropospheric ozone from space, Nature, 392, 168-171, 1998.

Orphal, J.: A critical review of the absorption cross-sections of $\mathrm{O}_{3}$ and $\mathrm{NO}_{2}$ in the $240-790 \mathrm{~nm}$ region, Part 1 . ozone, in ESA Technical Note MO-TN-ESA-GO-0302, ESA-ESTEC, Noordwijk, The Netherlands, 2002.

Orphal, J.: A critical review of the absorption cross-sections of $\mathrm{O}_{3}$ and $\mathrm{NO}_{2}$ in the $240-790 \mathrm{~nm}$ region, J. Phtotochem. Photobiol. A., 157, 185-209, 2003.

Orphal, J. and Chance, K.: Ultraviolet and visible absorption crosssections for HITRAN, J. Quant. Spectrosc. Radiat. Transfer, 82, 491-504, 2003.

Paur, R. J. and Bass, A. M.: The ultraviolet cross-sections of ozone, II. Results and temperature dependence, in: Atmospheric Ozone, edited by: Zerefos, C. S., Ghazi, A., and Reidel, D., Norwell, Mass., 611-616, 1985.

Rothman, L. S., Jacquemart, D., Barbe, A., et al.: The HITRAN 2004 molecular spectroscopic database, J. Quant. Spectrosc. Radiat. Transfer, 96(2), 139-204, 2005.

van $\operatorname{der}$ A, R. J., van Oss, R. F., Piters, A. J. M., Fortuin, J. P. F., Meijer, Y. J., and Kelder, H. M.: Ozone profile retrieval from recalibrated GOME data, J. Geophys. Res., 107(D15), 4239, doi:10.1029/2001JD000696, 2002.

van Roozendael, M., Loyola, D., Spurr, R. J. D., et al.: Ten years of GOME/ERS-2 total ozone data - The new GOME data processor (GDP) version 4: 1. Algorithm description, J. Geophys. Res., 111, D14311, doi:10.1029/2005JD006375, 2006. 